\title{
Health Related Quality of Life in Patients with Chronic Diseases
}

\author{
Afaf Merza Ahmed Ali Mohamed', Hasan Mohamed Ali Isa ${ }^{2, *}$
}

\begin{abstract}
Background: Chronic diseases impacted the different aspects of patients' life. This study aimed to measure health-related quality of life (HROOL) of patients with chronic diseases attending primary health care centres in Bahrain. Methods: This Cross-sectional study was conducted between September 2016 and January 2017 in five randomly selected primary health centres. Data was collected using a self-filled structured questionnaire (World Health Organization Quality of life-BREF (WHOQOLBREF) questionnaire) to measure the HRQOL. Scores of HROOL were calculated and relations between the scores and the sociodemographic data were explored using one-way ANOVA. Results: 337 questionnaires were received back with a response rate of $67.4 \%$. $169(50.1 \%)$ of the participants were females. The mean age (SD) was $52 \pm 11$ years. Most of the participants were married $(255(78.2 \%))$, retired $(115(34.1 \%))$ and educated $(309(91.7 \%))$. All the participants had at least three chronic diseases. The most prevalent chronic diseases were diabetes mellitus, dyslipidemia and hypertension. 161(48\%) participants reported having good quality of life and were satisfied with their health. The mean HROOL scores for physical, psychological, social and environmental domains were $63.8 \pm 18,63.9 \pm 18,67 \pm 22$ and $64 \pm 16$, respectively. Patients with diabetes, hypertension and hyperlipidemia tend to have the highest mean scores in all the domains. Patients with sickle cell disease and psychiatric diseases had the lowest mean scores in all the domains. Conclusion: Chronic diseases affect the HROOL of patients. Some diseases had more impacts on the HROOL than others. Patients with chronic diseases in Bahrain had an overall good quality of life.
\end{abstract}

Key words: $\mathrm{HRQOL}$, Quality of life, Chronic diseases, Non-communicable disease, Bahrain.

\section{INTRODUCTION}

\section{Afaf Merza Ahmed Ali Mohamed', Hasan Mohamed Ali Isa ${ }^{2, *}$ ${ }^{1}$ Public Health Consultant, Public Health Directorate, Ministry of Health, Manama, BAHRAIN. \\ 2Department of Pediatric, Arabian Gulf University and Pediatric Gastroenterology Consultant, Salmaniya Medical Complex, Manama, BAHRAIN.}

\section{Correspondence}

Dr. Hasan Mohamed Ali Isa,

Assistant Professor, Department of Pediatric, Arabian Gulf University and Pediatric Gastroenterology Consultant, Salmaniya Medical Complex, Manama, BAHRAIN.

Mobile no: +00973-66364449

Email: halfaraj@hotmail.com

History

- Submission Date: 19-04-2020

- Revised Date: 09-06-2020

- Accepted Date: 16-07-2020

DOI : 10.5530/ijmedph.2020.3.22

Article Available online

http://www.ijmedph.org/v10/i3

\section{Copyright}

(C) 2020 Phcog.Net. This is an openaccess article distributed under the terms of the Creative Commons Attribution 4.0 International license.
Worldwide, chronic diseases had increased significantly in the past decades. This was a result of improved living conditions and advances in medical treatment. Consequently, the number and the life expectancies of patients living with chronic diseases of have increased. ${ }^{1,2}$ Chronic diseases in general have slow progression and prolonged duration requiring continuous medical care. In United States, more than $40 \%$ of patients seen in primary health care setting have multiple chronic illnesses. ${ }^{3}$ Majority of chronic diseases have the potential to affect the overall health of patients and their quality of life. ${ }^{1}$ Studies showed an adverse effect of these diseases on patient's quality of life. ${ }^{1,4}$ One study even showed a larger effect on the quality of life with the presence of more than one disease. ${ }^{5}$ In addition to multimorbidity, other factors might also affect the patient's quality of life like age, sex, educational level and associated psychiatric diseases. ${ }^{6}$ Chronic diseases have impacts on different aspects of patients' life like perception of independence, social relationship, financial capacity and general wellbeing which are not measured routinely in health care visits. Understanding the relationship between quality of patient's life and their chronic diseases is important. ${ }^{7,8}$

Quality of life was defined by the world health organization (WHO) as the persons' view of his position in life in his own cultural environment and within his own value regarding his own expectations and goals. Health-related quality of life (HRQOL) describes the effect that any health condition and/ or its' symptoms exhibit on the individual's life. ${ }^{9,10}$ HRQOL questionnaires were used to measure the discrepancies between the objective health status and the one's subjective sense of health. ${ }^{7}$ The WHO in collaboration with 15 centres around the world has developed two tools to measure the quality of life which are the World Health Organization Quality of life-100 (WHOQOL-100) and World Health Organization Quality of life-BREF (WHOQOLBREF). ${ }^{9}$ Centers for Disease Control and Prevention in the United States had also developed their own tool to measure quality of life. ${ }^{3}$

Information gained from assessing the quality of life are of great value for public health and for health care systems. Assessment of patient's quality of life had become an established factor in assessing health care outcomes and in developing guidelines. ${ }^{11}$ HRQOL questionnaires might reveal the public views to guide the health care policies and to observe the progress of national health targets. ${ }^{11}$ The more we understand the effect of chronic diseases on patient's quality of life, the better will be the development of management strategies to control these diseases. ${ }^{7}$
Cite this article : Mohamed AMAA, Isa HMA. Health Related Quality of Life in Patients with Chronic Diseases.. Int J Med Public Health. 2020;10(3):104-9. 
HRQOL had been studied in many developed countries across the globe. Yet, the concept of HRQOL is not familiar in the Middle East and measuring it is not a common practice as reflected by the scarcity of related studies in this part of the world. ${ }^{12,13}$ Bahrain is an Arabic speaking country in the Middle East with a population of more than a million. ${ }^{14}$ Over the last few decades, Bahrain has experienced a dramatic economic growth and life style changes. Sedentary life style and high caloric diet lead to an increase in the prevalence of chronic diseases in this country. ${ }^{15}$ Chronic diseases are the major cause of mortality in Bahrain accounting for $79 \%$ of the overall deaths. The estimated prevalence of some chronic diseases like diabetes, hypertension and hyperlipidaemia in Bahrain were $13.5 \%, 38.2 \%$ and $40 \%$; respectively. ${ }^{16}$ Although there are well-structured non-communicable diseases (NCDs) clinics to care for patients with chronic diseases in Bahrain, measuring HRQOL is not incorporated in these clinics nor studied on a regular basis.

Although the prevalence of chronic diseases in Bahrain is high, studies about HRQOL are limited. Only few studies were published about quality of life in patient with kidney transplant, breast cancer, pulmonary diseases and sickle cell disease specifically. ${ }^{17-20}$ The main objective of this study was to measure HRQOL of patients with chronic diseases attending NCDs clinics in the primary health care centres in Bahrain.

\section{MATERIALS AND METHODS}

\section{Sample and setting}

This is a cross-sectional study which was conducted between September 2016 and January 2017. Patients from the 28 primary health care centres distributed across the five health governorates in Bahrain were gathered using a stratified random sampling method. Two health centres were randomly selected from each health governorate. In each of the selected health centres, there were specialized clinics to care for patients with chronic diseases; the NCDs clinics and the diabetic clinics. The sample size was estimated using an online sample size calculator at 95\% confidence level and 5\% confidence interval.

All eligible patients attending the NCDs and diabetic clinics during the study period were invited to participate. The eligibility criteria were being Bahraini, adult older than 18 years, competent in Arabic language and has one or more chronic diseases.

\section{Data collection procedure}

The data were gathered using a self-filled structured questionnaire, which was distributed to the patients by nursing staff who run the NCDs or the specialized diabetic clinics. The questionnaire consisted of two parts. The first part was related to sociodemographic data and inquired about the types of chronic medical conditions. The second part was the WHOQOLBREF questionnaire which was used to collect the data about HRQOL. The WHOQOL-BREF is a self-filled structured questionnaire scored in a 5-point Likert scale with the highest score representing better HRQOL. The questionnaire contains 26 questions; two general questions and 24 items assessing the four HRQOL domains. The two general questions are asking about the overall quality of life and the overall health status of the patient. The four domains of HRQOL are the physical, the psychological, the social relationship and the environment domains. Each domain is measured by subscale and the sum of all the subscales gives the overall HRQOL. The raw scores for the domains were calculated by adding the score of the questions related to these domains. These scores are then transformed into a scale between $0-100$ where zero is the lowest and 100 is the highest score. If more than two items of the domain questions were not answered, the domain score is discarded.

\section{Ethical consideration}

This study was conducted in accordance with the principles of Helsinki Declaration. The primary care medical research committee in ministry of health in Bahrain had approved this study. Participation in the study was voluntary and each patient has signed a written informed consent to be enrolled in the study. Patient's confidentiality was assured.

\section{Data analysis}

Statistical analysis was done using the statistical package for social science software (SPSS) version 20. Descriptive and inferential statistics were performed. Descriptive statistics were calculated for all the study variables. The frequency, mean, median, range and standard deviation (SD) were calculated. Summary of the scores were generated for the WHOQOL-BREF questionnaire by organizing the items into domains covered by the questionnaire. In computing the summary scores, patients with missing values were excluded from the analysis for that domain. One-way ANOVA was used to study the relationship between the four domains of the HRQOL and the sociodemographic variables. The Cronbach alpha test was used for all the 26 items in the HRQOL questionnaire to test for internal consistency. Statistical significance was set at $P<0.05$.

\section{RESULTS}

Out of 500 distributed questionnaires, 337 questionnaires were received back with a response rate of $67.4 \%$. Demographic data of the study participants showed that 169 (50.1\%) were females. (Table 1) Most of the participants were married (255 (78.2\%)), retired (115 (34.1\%)) and educated $(309(91.7 \%))$. The majority had either secondary school certificate (138 (41.8\%) patients) or university certificates (103 (31.2\%) patients). Most of the patients were non-smokers (232 (68.8\%)).

All patients in the study had three or more chronic diseases. (Table 2) Type 2 diabetes mellitus, dyslipidemia and hypertension were the most prevalent diseases and found in 228 (67.7\%), 157 (46.6\%), 153 (45.4\%) patients; respectively. Other chronic diseases like asthma, heart disease, back pain and joint pain were less prevalent in the study population.

Degrees of subjective overall quality of life perception and level of health of the participants were reviewed. One hundred sixty-two (48.1\%) participants rated their overall quality of life as being good, 89 males versus 72 females; while $72(21.4 \%)$ as being very good, 31 males versus 41 females. (Table 3) Regarding the satisfaction with health status, 160 (47.5\%) participants, 85 males vs 74 females, were satisfied with their health status; and $62(18.4 \%)$ participants, 34 males vs 28 females, were very satisfied. There were no significant differences between males and females regarding both questions $(P=0.172$ and $P=0.096$, respectively). Married patients had a better overall quality of life (186 $(77.5 \%))$ compared to divorced $(7(50 \%))$, widowed $(17(62.9 \%))$ or single $(15(57.7 \%))$ patients $(P=0.01)$. Yet, no significant difference in the satisfaction with the overall health status in relation to marital status. Retired patient $(92 / 106(86.8 \%))$ had an overall quality of life better than employed (73/95 (76.8\%)) and unemployed (64/107 (59.8\%)) patients $(P=0.003)$ and they were more satisfied with their health $(P=0.01)$. Nonsmoker patients $(176 / 222(79.3 \%))$ rated their overall quality of life better than smoker patients $(19 / 31(61.3 \%))(P<0.001)$. Non-smokers were also more satisfied $(166 / 224(74.1 \%))$ with their overall health compared to the smokers $(16 / 32(50 \%))(P=0.002)$.

The mean (SD) scores for the physical, psychological, social and environmental HRQOL domains are shown in Table 4. The relation between each domain scores and the sociodemographic variables are shown in Table 5. Males had better scores than females in terms of physical, psychological and environmental domains $(P<0.001, P=0.009$ 


\begin{tabular}{|c|c|c|c|}
\hline \multicolumn{2}{|r|}{ Variable } & \multirow{2}{*}{$\begin{array}{c}\text { Patients' } \boldsymbol{n} \text { (\%) } \\
\text { 53.1(11.68) }\end{array}$} & \multirow{2}{*}{$\begin{array}{c}\text { Total } \boldsymbol{n}(\%) \\
337(100)\end{array}$} \\
\hline Age & Mean (SD) & & \\
\hline & Median (range) & $54(22-85)$ & $337(100)$ \\
\hline \multirow[t]{2}{*}{ Gender } & Male & $166(49.3)$ & $335(99.4)$ \\
\hline & Female & $169(50.1)$ & $335(99.4)$ \\
\hline \multirow[t]{4}{*}{ Marital status } & Single & $28(8.6)$ & $326(96.7)$ \\
\hline & Married & $255(78.2)$ & $326(96.7)$ \\
\hline & Divorced & $15(4.6)$ & $326(96.7)$ \\
\hline & Widow & $28(8.6)$ & $326(96.7)$ \\
\hline \multirow[t]{3}{*}{ Job status } & Working & $99(29.4)$ & $328(97.3)$ \\
\hline & Not working & $114(33.8)$ & $328(97.3)$ \\
\hline & Retired & $115(34.1)$ & $328(97.3)$ \\
\hline \multirow[t]{5}{*}{ Highest educational level } & Not educated & $25(7.6)$ & $330(97.9)$ \\
\hline & Primary school certificate & $28(8.5)$ & $330(97.9)$ \\
\hline & Intermediate school certificate & $36(10.9)$ & $330(97.9)$ \\
\hline & Secondary school certificate & $138(41.8)$ & $330(97.9)$ \\
\hline & University & $103(31.2)$ & $330(97.9)$ \\
\hline \multirow[t]{6}{*}{ Highest university certificate } & Diploma & $35(10.5)$ & $332(98.5)$ \\
\hline & Bachelor's degree & $54(16.3)$ & $332(98.5)$ \\
\hline & Higher diploma & $7(2.1)$ & $332(98.5)$ \\
\hline & Master's degree & $6(1.8)$ & $332(98.5)$ \\
\hline & $\mathrm{PhD}$ & $2(0.6)$ & $332(98.5)$ \\
\hline & Not applicable & $228(68.7)$ & $332(98.5)$ \\
\hline \multirow[t]{3}{*}{ Smoking status } & Smoker & $36(10.7)$ & $289(85.8)$ \\
\hline & Non-smoker & $232(68.8)$ & $289(85.8)$ \\
\hline & Ex-smoker & $21(6.2)$ & $289(85.8)$ \\
\hline
\end{tabular}

$\mathrm{SD}=$ standard deviation, $\mathrm{PhD}=$ Doctor of Philosophy.

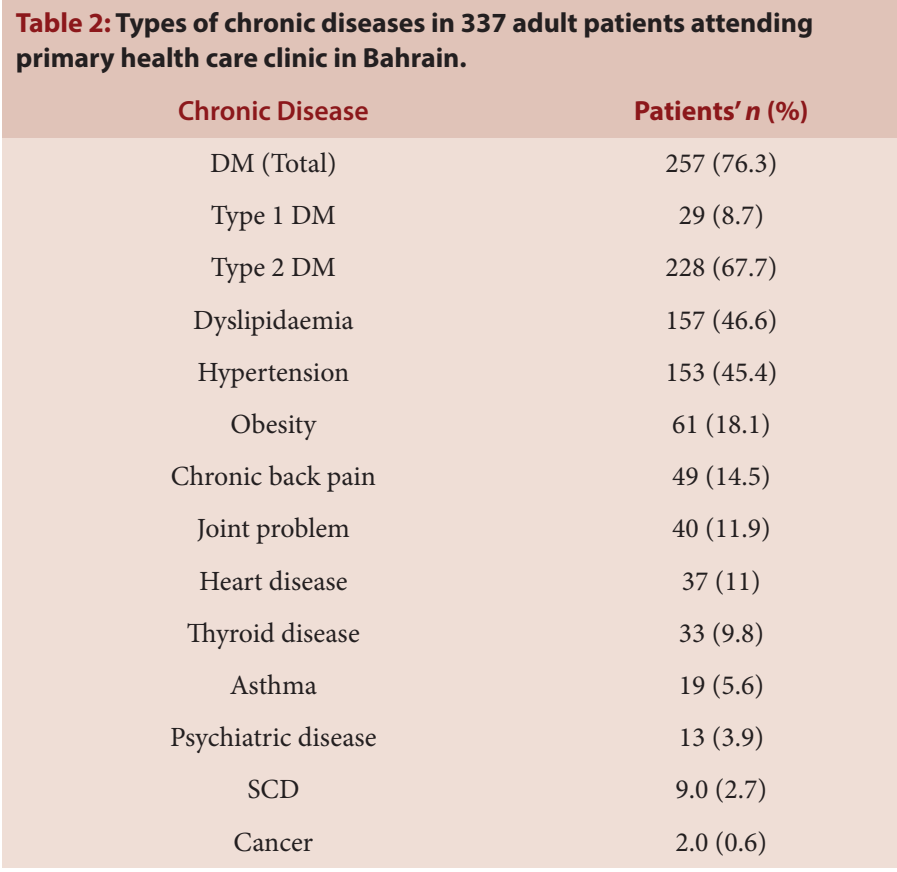

$\mathrm{DM}=$ diabetes mellitus, $\mathrm{SCD}=$ sickle cell disease.

\begin{tabular}{|c|c|c|c|}
\hline \multicolumn{2}{|c|}{ Variable } & \multirow{2}{*}{$\begin{array}{c}\text { Patients' } \boldsymbol{n} \text { (\%) } \\
4(1.2)\end{array}$} & \multirow{2}{*}{$\begin{array}{l}\text { Total } \boldsymbol{n}(\%) \\
317(94.1)\end{array}$} \\
\hline Overall quality & Very poor & & \\
\hline & Poor & $10(3.0)$ & $317(94.1)$ \\
\hline & Not good-not poor & $69(20.5)$ & $317(94.1)$ \\
\hline & Good & $162(48.1)$ & $317(94.1)$ \\
\hline & Very good & $72(21.4)$ & $317(94.1)$ \\
\hline \multirow[t]{5}{*}{ Level of health } & Not satisfied at all & $11(3.3)$ & $320(95)$ \\
\hline & Not satisfied & $45(13.4)$ & $320(95)$ \\
\hline & $\begin{array}{l}\text { Not satisfied-not } \\
\text { unsatisfied }\end{array}$ & $42(12.5)$ & $320(95)$ \\
\hline & Satisfied & $160(47.5)$ & $320(95)$ \\
\hline & Very satisfied & $62(18.4)$ & $320(95)$ \\
\hline
\end{tabular}


and $P=0.049$, respectively). Married participants had better scores in physical, psychological and social domains $(P=0.016, P=0.03$ and $P<0.001$, respectively) compared to other marital statuses. Working participants had better score in the physical, psychological and environmental domains $(P<0.001$ in all respective domains) compared to not working or retired patients. In the social domain, retired patients had better scores, but it was not statistically significant $(P=0.076)$. Educated patient and non-smokers had better scores than uneducated patients or smokers in all domains $(P<0.05)$.

Different chronic diseases affected the variable domains differently. (Table 6) Patients with diabetes, hypertension and hyperlipidemia tend to have better mean scores in all domains. Patients with sickle cell disease and psychiatric diseases had the lowest mean scores in all domains. The Cronbach alpha test showed a result of 0.877 .

\section{DISCUSSION}

Quality of life is an important topic in the care of patients with chronic diseases. In literature, there is a growing attention focusing on HRQOL of chronically ill patients because it can affect the patients' attitude toward the disease and its' treatment. ${ }^{1}$ In Bahrain, chronic diseases account for $83 \%$ of deaths annually. This study found that patients followed in the chronic disease clinics suffers from at least three chronic diseases. This might indicate the high prevalence of comorbidities among patients with chronic diseases and might explain the mortality statistics in Bahrain which showed that chronic diseases are the leading cause of mortality in the country. The high prevalence of comorbidities was also reflected in a study done on diabetic patients in Bahrain and found that two third of them had hyperlipidemia and one third had hypertension in addition to their diabetes. ${ }^{21}$ Similarly, a study to detect cardiovascular risk factors on workplace in Bahrain found high prevalence of diabetes, hyperlipidaemia

$\begin{aligned} & \text { Table 4: World health organization quality of life questionnaire } \\ & \text { (WHOQOL-BREF) domains of } \mathbf{3 3 7} \text { adult patients with chronic diseases } \\ & \text { attending primary health care clinic in Bahrain. }\end{aligned}$
$\begin{array}{ccc}\text { Domain } & \text { Mean (SD) } & \text { Median (range) } \\ \text { Physical } & 63.75(18.15) & 63(0-100) \\ \text { Psychological } & 63.89(18.33) & 69(0-100) \\ \text { Social } & 67.12(22.32) & 75(0-100) \\ \text { Environmental } & 64.20(16.05) & 63(13-100)\end{array}$

$\mathrm{SD}=$ standard deviation.

\begin{tabular}{|c|c|c|c|c|c|c|c|c|c|}
\hline \multicolumn{2}{|c|}{ Variable } & \multirow{2}{*}{$\begin{array}{l}\text { Physical } \\
\qquad 68(16.3)\end{array}$} & \multirow{3}{*}{$\begin{array}{l}P \text { value } \\
<0.001(\mathrm{CI} \\
4.3-12.4)\end{array}$} & \multirow{3}{*}{$\begin{array}{c}\text { Psychological } \\
66.8(17.7) \\
61.3(18.5)\end{array}$} & \multirow{3}{*}{$\begin{array}{c}P \text { value } \\
0.009(\mathrm{CI} \\
1.4-9.5)\end{array}$} & \multirow{3}{*}{$\begin{array}{c}\text { Social } \\
68.3(20.4) \\
66.2(24.3)\end{array}$} & \multirow{3}{*}{$\begin{array}{c}P \text { value } \\
0.421(\mathrm{CI} \\
-2.9-7.1)\end{array}$} & \multirow{3}{*}{$\begin{array}{c}\text { Environmental } \\
\qquad 66.1(15.1) \\
62.5(16.8)\end{array}$} & \multirow{3}{*}{$\begin{array}{c}P \text { value } \\
0.049 \\
\text { (CI } 0.02- \\
7.3 \text { ) }\end{array}$} \\
\hline Gender & Male & & & & & & & & \\
\hline & Female & 59.7 (19) & & & & & & & \\
\hline \multirow{2}{*}{$\begin{array}{l}\text { Marital } \\
\text { status }\end{array}$} & Divorced & $58.3(9.9)$ & & $55.5(17.6)$ & & $61.2(16.7)$ & & $55.9(16.5)$ & \\
\hline & Widow & $55.8(16.8)$ & & $60.3(14.8)$ & & $60.5(20.8)$ & & $60.4(15.6)$ & \\
\hline \multirow[t]{2}{*}{ Job status } & Working & $65.4(15.7)$ & $<0.001$ & $65.3(16.5)$ & $<0.001$ & $65.1(21.2)$ & 0.076 & $65.2(13.8)$ & $<0.001$ \\
\hline & Not working & $57.4(19.1)$ & & $57.5(18.5)$ & & $66.3(23.2)$ & & $58.6(17)$ & \\
\hline \multirow{3}{*}{$\begin{array}{c}\text { Highest } \\
\text { educational } \\
\text { level }\end{array}$} & $\begin{array}{l}\text { Intermediate } \\
\text { school }\end{array}$ & $62.7(16.1)$ & & $61.5(21.9)$ & & $60.9(26.2)$ & & $59.5(18.6)$ & \\
\hline & Secondary school & $63.9(18.8)$ & & $62.6(18.5)$ & & $69(21.7)$ & & $64.2(14.9)$ & \\
\hline & University & $67.3(15.5)$ & & 69.4(15.9) & & $69.4(18.3)$ & & $69.2(14.1)$ & \\
\hline \multirow{5}{*}{$\begin{array}{l}\text { Highest } \\
\text { university } \\
\text { certificate }\end{array}$} & Diploma & $66.3(17.3)$ & 0.754 & 68.4(15.9) & 0.02 & $71.8(21.6)$ & 0.673 & $70.2(14.5)$ & 0.014 \\
\hline & Bachelor's degree & $66.3(17.4)$ & & $68(16.6)$ & & $68.9(17.6)$ & & $66.9(14.9)$ & \\
\hline & Higher diploma & $62.5(15.6)$ & & $70.6(17.4)$ & & $59.3(10.4)$ & & $69.8(15.1)$ & \\
\hline & Master's degree & $66(3.3)$ & & 71.818 .4() & & $70.8(17.9)$ & & $75.2(9.56)$ & \\
\hline & Ph.D & $72(12.7)$ & & $87.5(17.7)$ & & $75(35.4)$ & & $75.5(17.7)$ & \\
\hline
\end{tabular}

$\mathrm{SD}=$ standard deviation, $\mathrm{CI}=$ confidence interval, $\mathrm{Ph} . \mathrm{D}=$ Doctor of Philosophy. 
Table 6: World health organization quality of life questionnaire (WHOQOL-BREF) domains of different types of chronic disease in 337 adult patients attending primary health care clinic in Bahrain.

\begin{tabular}{|c|c|c|c|c|}
\hline \multirow{2}{*}{ Type of chronic disease } & \multicolumn{4}{|c|}{ Quality of life domains, Mean (SD) } \\
\hline & Physical & Psychological & Social & Environmental \\
\hline Type 1 DM & $58.8(18.4)$ & $66.3(17.2)$ & $69.4(17.5)$ & $63.9(14.5)$ \\
\hline Type 2 DM & $65.3(18)$ & $65.1(17.6)$ & $68.5(22.7)$ & $65.7(16.1)$ \\
\hline Dyslipidemia & $61.2(18.8)$ & $62.6(17.8)$ & $64.5(23.7)$ & $64.4(15.6)$ \\
\hline Hypertension & $64.4(17.1)$ & $64.7(17.3)$ & $66.4(22.6)$ & $65.2(15.2)$ \\
\hline Obesity & $57.7(21.5)$ & $59.5(21)$ & $61.9(26)$ & $61.4(18.9)$ \\
\hline Chronic back pain & $52.8(20.3)$ & $61.9(19)$ & $62.1(25.8)$ & $61.3(17.2)$ \\
\hline Joint problem & $54.3(23.1)$ & $60.1(19)$ & $62(25.6)$ & $61.4(19.4)$ \\
\hline Heart disease & $52.6(23.7)$ & $58.4(21.9)$ & $52.3(28.3)$ & $62.4(19.6)$ \\
\hline Thyroid disease & $56.1(15.6)$ & $59.5(17.7)$ & $67.9(23.6)$ & $63.9(16.6)$ \\
\hline Asthma & $57.3(25.9)$ & $51.3(27.3)$ & $54(32.9)$ & $55.5(25.9)$ \\
\hline Psychiatric disease & $44(24)$ & $43.3(20.4)$ & $39.6(21.7)$ & $51.2(19.7)$ \\
\hline SCD & $48.8(26.9)$ & $57.9(17)$ & $47.1(34)$ & $49.3(12.2)$ \\
\hline Cancer & $50(8.5)$ & $75(8.5)$ & $69(0.0)$ & $69(8.5)$ \\
\hline Other chronic disease & $59.9(21)$ & $58.1(19)$ & $75(23.8)$ & $64.4(18)$ \\
\hline
\end{tabular}

$\mathrm{DM}=$ diabetes mellites, $\mathrm{SD}=$ standard deviation, $\mathrm{SCD}=$ sickle cell disease.

\begin{tabular}{|c|c|c|c|c|c|}
\hline Domain & Bahrain* & Pakistan & Indonesia & Kuwait & $\begin{array}{l}\text { Hong } \\
\text { Kong }\end{array}$ \\
\hline Physical & $63.8 \pm 18$ & 65 & 69 & 66.3 & 70 \\
\hline Psychological & $63.9 \pm 18$ & 67 & 66 & 63.9 & 65 \\
\hline Social & $67 \pm 22$ & 72 & 63 & 68.8 & 63 \\
\hline Environmental & $64 \pm 16$ & 55 & 58 & 65.4 & 61 \\
\hline
\end{tabular}

*the present study.

and hypertension. ${ }^{22}$ In contrast, a study about comorbidities and quality of life in European countries showed a lower rate of comorbidities of only $27 \% .^{23}$

Despite the comorbidities, the study population rated their quality of life as good and their HRQOL scores were relatively high when compared to similar studies in other countries. Participants of this study had HRQOL scores of $63.8 \pm 18,63.9 \pm 18,67 \pm 22$ and $64 \pm 16$ for physical, psychological, social and environmental domains respectively. However, a study from Gaza province on diabetic patients showed mean scores of 36.7, 34.8, 52.4 and 23 for physical, psychological, social and environmental domains respectively which were far lower than those of the present study. ${ }^{24}$ This could explain why poor health does not usually equate poor quality of life as some people are able to overcome limitations generated by the presence of their illnesses. ${ }^{5}$

HRQOL scores of the current study participants were good enough to be compared with scores of the general population in other countries (Table 7). Yet, a study on Kuwaiti general population showed a better score in physical domain but comparable scores on other domains. ${ }^{25}$ Furthermore, general population in Indonesia had higher scores in physical and psychological domains but lower scores in the social and environmental domains when compared to the present study population. ${ }^{26}$ Participants in the current study had higher scores in social and environmental domains when compared to general population of Hong Kong. ${ }^{27}$ They also scored higher in environmental domain when compared to Pakistani general population. ${ }^{28}$

Several studies showed differences in the HRQOL scores by sex. Males usually had better scores than females. Some domains were more affected than other by the sex of the patients. In physical, psychological and social domains males tend to score higher than females which was comparable to the result of the current study. ${ }^{25,26}$ However, other study showed better quality of life among females. ${ }^{5}$ Level of education is known to improve the HRQOL scores. In this study, educated patients had better scores in all domains compared to non-educated patients which is similar to other studies. ${ }^{23,26}$

In the current study, retired patients showed better overall quality of life and better scores in the social domain. This could be explained by that retired patients had more free time to socialize than do working individuals. On the other hands, the working participants had better scores on the physical domains. This could be explained by the presence of differences in the mean age of both groups and on the sex distribution. Working participants had lower mean age of 47 years than retired participants who had mean age of 58.9 years. Most of the working participants are males and generally males had better physical score than females.

Some chronic diseases had more negative impacts on the HRQOL than others and their effects on the domains varies by the type of disease. For example, mental disorders had shown to have the worst effect on the psychological and social domains. ${ }^{23}$ Though, in another study, the negative effect of the mental disorders had shown to affect all the domains. ${ }^{29}$ Similarly, in this study, the patients with mental disorders had lower scores in all domains. Respiratory diseases had the worst effect on the environmental domains, which is in line with the result of this study, where asthma patients had lower scores compared to other diseases. ${ }^{23}$

In relation to smoking status, smoking was found to negatively affect the HRQOL scores across the four domains when compared to non-smokers which is similar to the results of studies done in Brazil and United States. ${ }^{30}$ This study is limited by being conducted only among Bahraini patients attending the chronic disease clinics. This could explain why all the 
patients had more than one chronic disease. Another limitation is that the patients who are followed in primary care chronic disease clinics are less likely to have complications than those followed in secondary care clinics which might limit the generalization of this study results. Despite these limitations, this study is one of few studies about HRQOL among patients with chronic disease in Bahrain. It can form basis for further studies in the same field.

\section{CONCLUSION}

Chronic diseases affect HRQOL of patients. Some diseases had more impacts on HRQOL than others. Patients with chronic diseases in Bahrain had relatively good HRQOL. However, this field in research is relatively new in Bahrain. Further studies tackling the same topic using different HRQOL measurement instruments will help in enriching this field.

\section{ACKNOWLEDGEMENT}

The authors kindly acknowledge all nursing staffs working in the NCDs clinics in all local health centres, Bahrain for the great help in distributing the HRQOL questionnaires.

\section{CONFLICT OF INTEREST}

The authors declare no conflict of interest.

\section{ABBREVIATIONS}

HRQOL: Health-Related Quality Of Life; WHOQOL-BREF: World Health Organization Quality Of Life-BREF; ANOVA: Analysis Of Variance; SD: Standard Deviation; WHO: World Health Organization; WHOQOL-100: World Health Organization Quality Of Life-100; NCDs: Non-Communicable Diseases; SPSS: Statistical Package for Social Science Software.

\section{REFERENCES}

1. Megari K. Quality of life in chronic disease patients. Health Psychol Res. 2013;1(3):e27.

2. World Health Organization. Global status report on noncommunicable diseases 2010. Geneva: World Health Organization. 2011;176. [cited 2020 Apr 14 ]. Available from: https://www.who.int/nmh/publications/ncd_report2010/en/

3. Zack MM, Moriarty DG, Stroup DF, Ford ES, Mokdad AH. Worsening trends in adult health-related quality of life and self-rated health-United States, 19932001. Public Health Rep. 2004;119(5):493.

4. Trevisol DJ, Moreira LB, Fuchs FD, Fuchs SC. Health-related quality of life is worse in individuals with hypertension under drug treatment: Results of population-based study. J Hum Hypertens. 2011;26(6):374.

5. Wikman A, Wardle J, Steptoe A. Quality of life and affective well-being in middle-aged and older people with chronic medical Illnesses: A cross-sectional population based study. PLoS One. 2011;6(4):e18952.

6. Al-Maskari MY, Petrini K, Al-Zakwani I, Al-Adawi SSH, Dorvlo ASS, Al-Adawi S. Mood dysfunction and health-related quality of life among type 2 diabetic patients in Oman: Preliminary study. IJNPND. 2011;1(1):56.

7. Zhang X, Norris SL, Chowdhury FM, Gregg EW, Zhang P. The effects of interventions on health-related quality of life among persons with diabetes: $A$ systematic review. Med Care. 2007;45:820-34

8. $\mathrm{Xu} \mathrm{RH}$, Cheung AWL, Wong EL. Examining the health-related quality of life using EQ-5D-5L in patients with four kinds of chronic diseases from specialist outpatient clinics in Hong Kong SAR, China. Patient Prefer Adherence. 2017;11:1565-72.
9. World Health Organization. WHOQOL-BREF: Introduction, administration, scoring and generic version of the assessment. Geneva: World Health Organization. 1996;1-18. [cited 2020 Apr 14 ]. Available from: https://www. who. int/mental_health/media/en/76.pdf?ua=1

10. Ski CF, Thompson DR. Quality of life in cardiovascular disease: What is it and why and how should we measure it?. Eur J Cardiovasc Nur. 2010;9:201-2.

11. Bowling A. Research methods in health: Investigating health and health services, $4^{\text {th }}$ ed. New York, USA: McGraw Hill/Open University Press. 2014.

12. Campbell-Scherer D. Multimorbidity: A challenge for evidence-based medicine. BMJ Evid Based Med. 2010;15:165-6.

13. Grimaldi-Bensouda L, Begaud B, Lert F, Rouillon F, Massol J, Guillemot D, et al. Benchmarking the burden of 100 diseases: Results of a nationwide representative survey within general practices. BMJ Open. 2011;1:e000215.

14. Ministry of Health. Health statistics 2012. Bahrain: Ministry of Health. 2012 . [cited 2020 Apr 14 ]. Available from: https://www.moh.gov.bh/Content/Files/ Publications/statistics/HS2012/hs2012_e.htm

15. Mattke S, Hunter LE, Magnuson M, Arifkhanova A. Population health management and the second golden age of Arab medicine: Promoting health, localizing knowledge industries and diversifying economies in the GCC countries. Rand Health Q. 2015;5(1).

16. Ministry of Health. National non communicable diseases risk factors survey 2007. Bahrain: Ministry of Health. 2010. [cited 2020 Apr 14]. Available from: https://www.moh.gov.bh/Content/Files/Publications/X_28120131 35226.pdf

17. Jassim GA, Whitford DL. Quality of life of Bahraini women with breast cancer: A cross sectional study. BMC Cancer. 2013;13(1):212.

18. Kamel CA, Salih FA, Sequeira RP, Kamel E. Evaluation of quality of life in kidney transplantation patients in Bahrain. Arab J Psychiatr 2008;19(2):126-40.

19. Ali E, AlHalwachi FF, Khalil F, Hejab ZM, Almolem ZA, Mandil MA. Health-related quality of life in adults with sickle cell disease in the Kingdom of Bahrain (FPRP). Saudi J Med. 2017;2:3-14. DOI: 10.21276/sjm.2017.2.1.2

20. Al-Moamary MS, Tamim HM, Al-Mutairi SS, Al-Khouzaie TH, Mahboub $\mathrm{BH}$, Al-Jawder SE, et al. Quality of life of patients with chronic obstructive pulmonary disease in the Gulf Cooperation Council countries. Saudi Med J. 2012;33(10):1111-7.

21. Almuhanadi S, Board A, Board I, Alsuliti M, Alhennawy $H$. Assessment of diabetic patients knowledge and comorbidities. Bahrain Med Bull. 2017;39.

22. Al-Nooh AA, Abdulabbas AAA, Wood D. The prevalence of cardiovascular disease risk factors among employees in the Kingdom of Bahrain between October 2010 and March 2011: A cross-sectional study from a workplace health campaign. Cardiol Res Pract. 2014;832421.

23. Tuzun $H$, Aycan S, Ilhan MN. Impact of comorbidity and socioeconomic status on quality of life in patients with chronic diseases who attend primary health care centres. Cent Eur J Public Health. 2015;23(3):188-94.

24. Eljedi A, Mikolajczyk RT, Kraemer A, Laaser U. Health-related quality of life in diabetic patients and controls without diabetes in refugee camps in the Gaza strip: A cross-sectional study. BMC Public Health. 2006;6(1):268.

25. Ohaeri JU, Awadalla AW, Gado OM. Subjective quality of life in a nationwide sample of Kuwaiti subjects using the short version of the WHO quality of life instrument. Soc Psychiatry Psychiatr Epidemiol. 2009;44(8):693-701.

26. Purba FD, Hunfeld JAM, Iskandarsyah A, Fitriana TS, Sadarjoen SS, Passchier J, et al. Quality of life of the Indonesian general population: Test-retest reliability and population norms of the EQ-5D-5L and WHOQOL-BREF. PLOS One. 2018;13(5):e0197098.

27. Wong FY, Yang L, Yuen JWM, Chang KKP, Wong FKY. Assessing quality of life using WHOQOL-BREF: A cross-sectional study on the association between quality of life and neighborhood environmental satisfaction and the mediating effect of health-related behaviors. BMC Public Health. 2018;18(1):1113.

28. Lodhi FS, Montazeri A, Nedjat S, Mahmoodi M, Farooq U, Yaseri M, et al. Assessing the quality of life among Pakistani general population and their associated factors by using the World Health Organization's quality of life instrument (WHOQOL-BREF): A population based cross-sectional study. Health Qual Life Outcomes. 2019;17(1):9.

29. Chang YC, Yao G, Hu SC, Wang JD. Depression affects the scores of all facets of the WHOQOL-BREF and may mediate the effects of physical disability among community-dwelling older adults. PLOS ONE. 2015;10(5):e0128356.

30. Ridner SL, Keith RJ, Walker KL, Hart JL, Newton KS, Crawford TN. Differences in quality of life among college student electronic cigarette users. AIMS Public Health. 2018;5(4):454-62. 